\title{
Minority students' responses to racism: The case of Cyprus
}

\begin{abstract}
While research has focused on the role of racism in (re)producing ethnic/racial inequalities in education, there is very little research that investigates how variability in minority students' responses to racism can be explained. By using an ecological approach to integrate existing research on actors' responses to racism, this study finds that researchers have generally neglected factors and processes situated at the micro and meso-levels of analysis. Qualitative interview data with Turkish-Cypriot children enrolled in schools in the predominantly Greekspeaking part of the Republic of Cyprus is used to investigate their strategies in response to racism and the factors that explain the observed variability in their responses. The findings suggest the importance of and interactions between factors situated at different levels of analysis, including the level of organizations and social groups and face-to-face interactions in explaining variability in young people's responses to racism.
\end{abstract}

Key words: racism, coping, qualitative research, Cyprus, schools

Cite as: To cite this article: Peter A. J. Stevens, Panayiota Charalambous, Evgenia Mesaritou, Spyros Spyrou, Lore Van Praag, Fanny D’hondt, Roselien Vervaet \& Mieke Van Houtte (2015): Minority Students' Responses to Racism: The Case of Cyprus, British Journal of Educational Studies, DOI: 10.1080/00071005.2015.1120271 


\section{Introduction}

Despite the abundance of research on racism in sociology of education, and the importance attached to racism as a primary cause of persisting social inequalities, there is very little research that investigates the variability in students' responses to racism. Most of the research in this area restricts its focus on ethnic or racial minority students' resistance to perceived oppression through the adoption of anti-school attitudes and forms of behaviour. Since social psychological research seems to relate actors' coping strategies to their psychological wellbeing (see: Brondolo et al., 2009), it is important to develop a greater understanding of how the social context informs students' choices for coping with racism. This article builds on a rich and important area of sociological and social psychological research on race and ethnic inequalities in education by investigating students' responses to racism in particular inand out-of-school contexts and the factors that explain the perceived variability in students' responses to racism.

Social psychological research tends to focus primarily on the direct and moderating effects of ethnic minorities' strategies in response to racism on educational and particularly (mental) health outcomes (for a review, see: Brondolo et al., 2009). While findings in this area of research are often contradictory and inconclusive, there is some evidence to conclude that a strong attachment to positive ethnic or racial identities (e.g. Wong et al., 2003), availability of social support (e.g. Swim et al., 2003) and active confrontation of racism (e.g. Hyers, 2007) are to some extent associated with more positive outcomes. Although there is relatively little social psychological research that aims to explain variability in actors' strategies in response to racism, studies in this area look primarily at the importance of individual level characteristics, including: the intensity and nature of the threat, the perceived degree of intentionality of the perpetrator, the potential consequences of the act and of the coping response and the availability of resources to assist the target (e.g.: Scott, 2004). 
One of the most widely cited theories that focuses explicitly on minority students' responses to racism is Ogbu's cultural-ecological model (Ogbu, 1990). According to this theory, voluntary immigrants (e.g. Asian Americans) respond to racism by opting for instrumental strategies (working hard in school, accommodating the culture and identity of the dominant group) because they compare their position with people in their country of origin. As a result, they have more optimistic views about being successful despite the occurrence of racism. In contrast, involuntary migrants (e.g. African Americans) respond to racism by resisting cultural and identity assimilation and developing anti-school cultures and oppositional identities, because they compare themselves with the white majority group and consider the historical relationship of oppression that marks the relationships with the dominant group. As a result, they see racism more as unavoidable and less manageable (Fordham and Ogbu, 1986). Hence, this theory points to macro-structural group experiences, related to migration processes and their treatment by the dominant group, which interact with macro-cultural ethnic and racial minority cultures to influence racial and ethnic minority groups' collective responses to racism.

However, this theory has been criticized for its failure to explain variability between ethnic and racial minority group members in their responses to racism (e.g.: Downey, 2008). First, a large body of qualitative, ethnographic case studies in education point to the importance of students' social background characteristics, related to their social class, gender and race/ethnicity and interactions between these characteristics in developing particular individual and group responses to racism (e.g.: Fuller, 1984, Mac an Ghaill, 1988, Sewell, 1998). While most of these studies are merely descriptive and do not seek to develop a theoretical explanation of why students adopt particular responses to racism, other studies show how families (e.g.: Stevenson, 1998) and religious organizations (e.g.: Rhamie, 2007) through socialization, make particular cultural frames of reference available to ethnic and 
racial minority youth that stimulate them to respond to racism by both resisting and accommodating adaptation to dominant group identifications, values and norms.

While there is very little research that investigates how particular school characteristics and processes impact on students' responses to racism, some researchers (e.g.: Gillborn and Youdell, 2000) argue that processes and structures of ability grouping (i.e. the differentiation of curriculum and pedagogy according to students' measured ability) can be perceived as a form of institutional or structural racism as they lead to an over-representation of ethnic and racial minorities in lower status ability groups. As a response to their lower status and lower teacher expectations and standards of pedagogy, these students are more likely to further develop anti-school cultures and lower educational outcomes.

The variety of characteristics and processes associated with ethnic minorities' responses to racism, ranging from individual level to macro-sociological level features, justify the use of an ecological approach in investigating students' responses to racism. This approach has its origins in developmental psychology (Bronfenbrenner, 1979) and classifies environmental context measures according to the level of analysis in which they are situated. Applying this approach means that researchers investigate the importance of and interactions between characteristics and processes situated at different levels of analysis, including: micro-sociological interactions between individuals (e.g. between teachers and students); which are embedded in institutions and organizations (e.g. families and schools) situated at the meso-level of analysis; which are in turn embedded in broader, macro-level social contexts related to structural characteristics between dominant and minority groups (e.g. social class differences and reception policies). These characteristics and processes interact in turn with individual-level characteristics related to individuals' frames of reference (i.e. their beliefs, attitudes and aspirations) and associated behaviours (Stevens and Görgös, 2010), including the way in which they respond to racism. 
The following conclusions can be drawn from reviewing research on strategies in response to racism through an ecological lens: First, there is very little research that considers how different levels interact with each other in stimulating young people to respond to racism in particular ways. Second, although research focuses on the importance of specific institutions (e.g. the family) and social organizations (e.g. the school), these studies are an exception with the majority of research focusing either on macro-sociological features or individual social psychological characteristics. Third, the conceptualization of actors' strategies in response to racism is often problematic in research, with (sociological) research often reducing students' responses to racism as either pro/anti particular cultural frames of reference and related forms of (pro- or anti-school) behaviour. While social psychological research often uses more sophisticated and complex conceptualizations and measurements of actors' coping strategies, the classifications used are not always clearly motivated, often overlap and do not sufficiently consider the social context in which these coping strategies are embedded, which can in part explain the contradictory findings of research in this field (Brondolo et al., 2009, Mellor, 2004).

This study builds on this developing field of research by exploring more inductively how ethnic minority students respond to racism in different contexts and how variability between students' responses to racism can be explained by (interactions between) factors and processes mainly situated at the meso-level (in- and out of school contexts) and micro-level (social interactions between individuals). More specifically, this study looks at data from qualitative interviews with Turkish-Cypriot ethnic minority students (TC hereafter) in two private secondary schools in the Republic of Cyprus (in the southern, Greek-speaking part of the island). Our analysis explores the experiences of this group of students with racism from students and teachers both at school and from peers outside school, the strategies they claim 
to adopt in response to such (and imagined) experiences and the factors that seem to explain the observed variability in students' responses to racism.

\section{Methods}

This paper reports on qualitative case-study research carried out in two Greek-Cypriot, private, English speaking, co-educational, multicultural secondary schools which, for the purposes of this study will be called Green Lane and Red Brick [1]. Both schools are situated in southern, mainly Greek-speaking, unoccupied part of the divided capital of Nicosia and attract mainly students from middle and higher social class backgrounds. The vast majority of students attending these schools aim at obtaining qualifications that will allow them to study in universities in the UK and the US. Green Lane is a large school (1022 students on roll) with the majority of students coming from the Greek-Cypriot majority (72\%) and a minority from Turkish-Cypriot (15\%) or other ethnic minority backgrounds (13\%) [2]. In contrast, Red Brick is a small school (206 students on roll) and ethnically more heterogeneous (46\% GreekCypriot, $15 \%$ Turkish-Cypriot and 38\% of other ethnic background). Both schools are similar to each other, but different to most (state) schools in Cyprus, in that the language of instruction is English. In addition, both schools are largely independent from government control in relationship to their organization and curriculum. As a result, the findings of this study cannot be generalized to public schools in Cyprus.

Our analysis focuses mainly on the Turkish-Cypriot students who live in the northern, Turkish-speaking part of Cyprus but who go to either Green Lane or Red Brick. This group of students (enrolled in years 2, 3 and 4 of secondary education or 13-16 year olds) was selected because it constitutes a theoretically interesting case due to the historical inter-ethnic conflict between the Greek-Cypriot and Turkish-Cypriot communities. More specifically, Cyprus in 1974 was annexed by the United Kingdom in 1925, and following the dissolution 
of the Ottoman Empire, made a Crown Colony. Cyprus became independent in 1960, but after the invasion of the Turkish army and the occupation of the northern part of the island, Cyprus became a de facto divided society, with the Greek-Cypriot residing in the southern part of the island and the Turkish-Cypriot community in the northern part. While movement across the buffer zone has been eased since 2003, the two communities live generally separated from each other with relatively few interactions between Turkish- and Greekspeaking citizens from both communities (Vryonides and Spyrou, 2014). Considering the political tension between the Turkish and Greek-speaking communities in Cyprus, we can expect the Turkish-Cypriot students included in this study to experience inter-ethnic hostility and racism, particularly as they attend a school situated in the southern, mainly Greekspeaking part of the island. Furthermore, the middle or high social class background of this group of students makes our sample interesting to compare with other studies, which usually discuss the cases of underprivileged ethnic minorities of lower social-class background. These differences between the two selected schools in terms of ethnic composition and size, allows us to explore the importance of their compositional characteristics for the development of students' experiences of racism and their responses to such experiences.

More specifically, our sample consisted of interviews with 15 TC students in Green Lane and 15 TC students in Red Brick (seven male and eight female students in each school). While we interviewed a similar group (in terms of size and gender and social class composition) of GC peers in each school, this data is only used in one particular section of this article. Students were allowed to take the interview with one (TC) friend and interviews typically lasted between $40-60$ minutes. All students and parents provided their informed consent and all data has been anonymized for the purposes of confidentiality. The data discussed in this paper come mainly from the part of the interview which focused on students' strategies in response to racism. More specifically, all students were asked to 
discuss how they had responded in case they experienced incidents of racism in the past; or how they would respond to an imagined incident of racism from: a) peers in school, b) teachers in school and c) strangers outside school. This allowed us to investigate students' coping strategies in relation to different social contexts and power relationships, something given little attention in the literature so far (Brondolo et al., 2009).

After the data was transcribed, the principal author analysed the data applying a Grounded Theory approach, aiming at developing a substantive theory related to our particular research setting, through inductive analysis of qualitative data (Glaser and Strauss, 1967). Using the qualitative data analysis software NVivo 9, research categories were developed very much in line with Glaser's (1992) more open approach to coding in Grounded Theory, in which the different levels of analysis that are stipulated in an ecological approach functioned very much as a 'coding family' (Glaser, 1992), stimulating the process of identifying and developing codes.

Furthermore, as our coding also pointed to the internal validity or credibility of Mellor's (2004) classification of coping styles to racism, this study used this classification in analysing actors' responses to racism. This classification is based on a qualitative study of 34 Indigenous Australians, which explored their experiences and responses to racism, in terms of their emotions and behaviour. Specifically, Mellor (2004) distinguished three broad categories of coping styles, which differ in terms of their function (rather than their content):

(1) defensive coping styles (aimed at protecting the self, e.g. displaying acceptance, withdrawal, denying identity, attempting to achieve);

(2) controlled coping styles (aimed at exercising self-control e.g. ignoring, containing or imagining responses); 
(3) counter-attacking coping styles (aimed at confronting racism e.g. teaching the racist, seeking revenge, asserting one's rights and/or identity).

This classification of strategies according to their function also has additional, theoretical relevance as particularly counter-attacking strategies have been associated with better psychological outcomes compared to emotion-focused strategies (Brondolo et al., 2009).

\section{Findings}

This section starts with a discussion of TC students' experiences of racism in and out of school (3.1.) and then moves on to examine their responses to lived or imagined experiences of racism (3.2.) and the factors that seem to inform students' preferences for specific coping strategies in particular contexts (3.3.).

\section{1. Experiences of racism}

Students were asked if they experienced racism (a) from students and teachers inside the school and (b) from people outside school. In contrast to Red Brick, TC students at the Green Lane reported more regularly incidents with peers in school involving:

(a) deliberately showing nationalistic or religious symbols to TC students (e.g. showing the Greek flag drawn on their pencil cases in the classroom).

(b) verbal abuse, in the form of: (i) insults (e.g. 'Turks out of Cyprus') said in English or in Greek (which the TC students usually cannot understand but interpret as abusive and racist); and/or (ii) ridicule (e.g. by making fun of a Turkish name). 
(c) physical abuse: one incident in Green Lane that a TC student boy claimed to have been tackled very hard and injured on purpose by a GC student in football

(d) destroying or damaging property: one incident in Green Lane where a TC student found pages ripped off from his Turkish language folder.

Taken together, TC students from Green Lane reported more incidents of racism by GC students and experienced more hostile expressions of racism. Furthermore, in the case of Red Brick, the reported experiences of racism by GC students mostly relate to a small group of five-six students in a particular class and year-group, while in Green Lane these experiences appear as more wide-spread, involving a larger group of students from different years and class-groups.

In both schools, a minority of students reported incidents of racism with teachers, all of which related to a few specific teachers in each school who were accused of treating TC students in a racist way, mainly by:

(a) treating them less fairly (e.g. more readily allowing GC students to play basketball compared to TC students);

(b) showing disrespect to TC students (e.g. talking in Greek to GC students in the classroom).

Usually, these teachers' alleged status as racists was not clear and sometimes even disputed between TC students, as these teachers were perceived to express their racism in a less overt or more implied, hidden fashion. However, apart from these isolated incidents, and in line with Stevens' (2008) analysis in a different context, TC students seemed to have very few experiences with teacher racism and were generally very positive about their teachers.

Finally, as to students' experiences with racism outside the school, while in both schools only a third of the student sample narrated such incidents, these appeared much more 
serious in nature, usually involving verbal or physical abuse by GC people. More specifically:

(a) in Green Lane, there were three reported incidents involving a group of GC people often peers - expressing offensive language and threatening behaviour towards TCs.

(b) in Red Brick, there were two reported incidents: one involving GCs throwing stones at the car in which a TC student was driving with his family; and one involving a GC hurling abuse to a TC student, because of his Turkish football team T-shirt.

Overall, our sample of TC students shows considerable variability- also between the two schools - in terms of students' experiences of racism in the school and outside. In what follows, we discuss how students respond to these experiences of racism and the factors and processes that seem to influence students' choice of particular strategies in response to racism.

\subsection{Responding to racism}

The following key differences can be observed in analysing students' responses to racism:

(1) Students from Red Brick show more variability in their responses to racism from students and are more likely to opt for counter-attacking strategies (usually by 'educating the racist', for instance by telling them that they are wrong to say such things); while most of their peers in Green Lane usually first respond in a more controlled fashion (i.e. 'biting their lip') and then report the incident to the senior management team.

(2) In both schools, students are much more likely to initially control their response to teacher racism. However, at the same time they find it more difficult to control their behaviour and are more likely to also opt for more intensive counter-attacking responses, either as an immediate response or as a follow-up response. 
(3) Students are much more likely to opt for defensive and/or controlled strategies in response to racism from strangers outside the school context (typically by ignoring and/or avoiding the racist people), compared to their responses to racism from students and teachers in school.

These findings strengthen the validity of Mellor's (2004) inductively constructed and function-based classification of ethnic minorities' responses to racism. It also builds on Mellor's classification by showing that actors' responses to racism are complex and contextspecific, in that students can use various coping strategies with a different focus in combination in various contexts; something that is usually not recognized in the research literature which often focuses on a single (dominant) response to racism (Brondolo et al., 2009).

\section{3. Factors influencing students' strategies in response to racism}

The following sections will look at the factors that can help us explain TC students' responses to racism from students and teachers in Red Brick and Green Lane and from strangers outside the school.

\subsubsection{Students' responses to racism from students inside the school}

One factor that appears important in explaining differences in TC students' responses to racist incidents from their peers in the two schools, is the (perceived) size of the school population and its composition in terms of ethnicity. As we have seen in section 2 , the student population in Green Lane is more than five times the size of Red Brick; it has a bigger percentage of GC students; and is generally less heterogeneous in terms of ethnic composition compared to Red Brick. As a result, many TC students in Green Lane expressed 
a strong reluctance to confront racist GC peers directly, as they felt outnumbered and scared for possible repercussions from GC students:

Researcher: Now imagine that somebody is racist to you, a student in school. How would you respond?

Karmen: (...) I will avoid communicating as my friend said, because I know that (...) I can't respond with another aggressive response because I'm the minority in school. I mean there are like 1000 Greek people here and like 150 Turkish people (...).

(Interview Green Lane)

While several TC students interviewed at Green Lane explicitly referred to the possibility of being 'beaten up' by GC students if they would respond to racism with a counter-attacking strategy, the fear of a possible retaliation by GC peers was never raised in the case of Red Brick.

Students in Red Brick were much more likely to refer to their 'friends' (which also included many more GC students) as a source of social (peer) support in dealing with inschool racism compared to their TC peers in Green Lane. Often the mere presence of TC friends in the classroom seemed to function as a preventative force against racism, since TC students were more likely to report experiences of racism in cases when there was no other TC student in the classroom. Sometimes friends were mentioned as a source of support in dealing with potential physical fights that developed out of racist incidents, but also as a 'passive' source of support to which students could fall back to when feeling excluded from GC students. The more multicultural make-up and the smaller size of Red Brick school also seemed to make TC and GC friendship groups and students in general more interconnected, 
with the result that incidents of racism seemed less likely to further polarize TC/GC in-out group tensions.

While the school's size and composition may explain the choice of a controlled strategy as an immediate response to a racist incident, the schools' policy in response to racism emerged as an important factor in understanding the choice of a counter-attacking strategy (reporting incident to school management), as a second stage in the responses of TC students in Green Lane. It was remarkable that in almost all the interviews in Green Lane, students referred to a particular teacher (Mrs Orange) who was part of the senior management team and was considered a natural point of contact in reporting racist incidents. In addition, most students in Green Lane referred to assemblies and presentations organized by Mrs Orange in which they discussed racism, its relation to bullying and the school's policy against bullying and racism. The school's formal anti-bullying and anti-racist policy and its strict enforcement as well as the visible point of contact for students that Mrs Orange provided seem to have made it more likely for TCs to report incidents of perceived racism occurring in Green Lane. However, in Green Lane it was also the case that the majority of GC students interviewed felt that the school overprotected TC students, that TC students took advantage of this system (by reporting many incidents of racism) and that as a result GC students were often wrongly accused of racism:

Researcher: And what do you think of what the school does in terms of policies?

Maria: The school is wrong.

Researcher: Yeah? In what way?

Maria: They think that we are fighting with each other and that we hate each other (...) they make this [hating each other] happen because when they make assemblies they talk us about the Turkish-Cypriots and they say "we will interview them every week" 
[Lefki: yes], yes, "we will interview them every week and ask them if you harm them" and with this way if someone likes them [the TC students] the teachers make us don't like them.

(Interview Green Lane)

GCs' claims that TCs received a more preferential treatment in Green Lane were not only caused by the implementation of anti-bullying (racism) policies that they felt were primarily targeted to GCs, but also because students in Green Lane were often of the opinion that school policies and teachers' practices were more politicised in nature, or intended to impose particular party-political views and related ideologies, as political conflicts between left and right wing teachers were more apparent in Green Lane. As students generally expected the school 'not to brainwash' young people with political ideologies, they were more likely to oppose policies that were considered as having a political agenda, particularly those associated with political parties that they opposed (something that is discussed more in detail somewhere else: Stevens, 2016).

In Red Brick students mentioned the principal and the teacher of Religious Education as two points of contact in that school that could deal with incidents of racism effectively. Hence, despite the lack of a strict and formal anti-racist policy in Red Brick, TC students knew where to go in case they experienced racism and felt supported, while none of the GC students of the school reported to be treated less fairly or targeted by the school. In sum, while both schools were successful in making TC students feel protected against racism, it seems that Green Lane's more formal policy stimulated TCs to respond to racism in a more uniform way, by reporting such incidents to Mrs Orange. However, the same formal anti-racism policy and GCs' perception that such policies were politically driven, had the unintended 
consequence of making the availability and use of such support become an issue that further polarized relationships between TC and GC students.

Additionally, in comparing both schools, it seemed that Green Lane applied its policies in amore inconsistent way, in that they seemed to allow more room for expressions of racism, particularly in relationship to the expression of nationalistic and/or religious symbols:

Researcher: Now if somebody would write let's say a Greek flag on his or her planner?

Baran: Yeah, they do that quite a lot: five planners in the class are like that, I counted them.

\section{(...)}

Researcher: And how do teachers respond to that?

Baran: Well, technically they can't really do anything to the planners but you are not allowed to say that loud or show it to somebody else, although they do that but if the teacher doesn't see it she or he cannot really do something.

(Interview Red Brick)

Thus, while Green Lane did not punish the display of national or religious symbols on personal property, the school, punishes the deliberate use of these symbols against the TC students. In sharp contrast, the expression of such symbols was prohibited in Red Brick:

Researcher: Do you think that if there is racism, the school would take it seriously?

Vedat: Yes they take it very seriously.

Researcher: How can you see that?

Vedat: Because one day as I said they drew flags on their bags, Mr Green saw this and he told the guy "you have to wrap this out or put Tipp-Ex on it". 
Researcher: So, they are not allowed to do that?

Vedat: No, they are not allowed.

(Interview Red Brick)

Therefore, this contradiction between enforcing a strict anti-racist school policy and, at the same time, allowing the expression of nationalistic and religious symbols may have unintentionally polarized the relations between TC and GC students. This factor, together with the politicized nature of school policies and the school's ethnic school composition could explain why TC students in Green Lane felt less inclined to opt for counter-attacking strategies and chose to first 'bite their lips' and then report the incident to the senior management team.

\subsubsection{Students' responses to racism from teachers inside the school}

Our analysis indicates that the more polarized response to teacher racism (see 4.2) might relate to the widespread student perception that teacher racism has more negative consequences for both the teacher and the students who experience it. First, students acknowledge that teachers have more power than students and that, as a result, racist actions of teachers can have more dire consequences for students and/or that teachers can retaliate more forcefully against students' accusations of teacher racism. Students claimed that standing up to racist teachers can have negative consequences for the student - as teachers 'can punish you', 'are more believable' -, something that seems to stimulate more defensive and controlled strategies on the part of the students.

However, at the same time, a central role-expectation of teachers is that they treat students fairly. Teachers 'should treat everybody equal', something that students often stressed when comparing the role of the teacher with that of the student:

Researcher: And if it was a teacher? 
Gona: I would feel really, really bad because I could excuse the students because they were raised up to think in such a way by the parents but I would think that teachers should know better.

(Interview Green Lane)

In the above excerpt we see that students consider racism coming from teachers as more morally wrong compared to that from students. The general expectation that teachers should not be racist might explain the more surprised and emotional reactions that we encountered in the accounts of many students, when discussing experienced or imagined incidents of teacher racism:

Researcher: And what would you do if a teacher was racist to you?

Hadis: Sorry?

Researcher: If a teacher was racist to you?

Pirnal: That would be for the school board.

Hadis: I would make his or her life a living hell!

Researcher: Really?

Pirnal: Yeah, I would not tolerate that because this is like just too far.

Researcher: And what would you do?

Pirnal: I would tell my mom because she would be actually REALLY upset about it. (Interview Green Lane)

Hadis initially responded in disbelief to our question and states that he would respond immediately in a counter-attacking way. Pirnal, who in the same interview would 'stay calm' when experiencing racism from students, considers teacher racism as 'just too far' and states that he would report it to his mother and to the Parents Association. The institutional structures also encourage this response, since students feel that they have the authority to 
make official complaints, which can result in the teachers' punishment, including them being fired. In addition, some students argued that teachers have no interest in being racist to students as their status depends on their students' grades, regardless of their ethnic background. Hence, the perception that teacher racism is morally wrong and against the teachers', students' and the school's interests stimulates students to actively respond to teacher racism, especially in school contexts where the senior management supports students in making claims against teacher racism.

A factor that seemed to constrain students from (immediately) counter-attacking teacher racism is a strong sense of respect for the authority of adults - and teachers especially. Many TC students interviewed argued that you could not talk back to a racist teacher because 'she's our teacher' or 'you don't really talk to your teacher that way'.

Furthermore, most of the students interviewed seemed to have very high educational expectations and aspirations and had managed to obtain high exam scores - in other words, to turn their high expectations into high achievement. It seems that these expectations prevented them from behaving in a manner that could be interpreted as racist or responding to racism in counter-attacking ways, other than reporting the incident to the senior management. Some students argued that being punished for racism 'could follow your whole career', since this could end up in school report cards send to prospective universities. Similarly, TC students refrained from counter-attacking racist students personally, as this would be registered as bullying or racism on their part too.

Another factor that might have enabled students' eagerness to confront teacher racism might relate to their language knowledge and skills. None of the students interviewed gave the impression of feeling uncomfortable with English as a language of communication. However, although language was not experienced as a barrier in our predominantly middleto-high social class student sample, this might not apply in the case of newly arrived 
immigrant students and/or students from working class backgrounds who are probably less likely to feel comfortable in talking to the teacher in ('proper') English and/or Greek (Lareau, 1999 (1987)). At the same time, students consider their knowledge of languages that are not known by their teacher(s) as a valuable resource that can be employed as part of a more counter-attacking coping style:
Abbas: I remember a friend (...) and [her] form tutor was talking Greek in class so she turned to talk Turkish with a Turkish-Cypriot friend and the form tutor told her to "shut up", and then she said to the form tutor: "If you talk Greek, a language other than I understand I will talk Turkish to my friends" and she got a pink slip (report card), so... (Interview Green Lane)

Classic ethnographic studies conducted in the UK on school racism frequently refer to the use of Patois as a language of communication by African-Caribbean students in resisting experiences of racism from white, British teachers (e.g.: Gillborn, 1990, Mac an Ghaill, 1988). However, the mainly middle-to-high social class background of students in Green Lane might explain why these students refrained to strategies related to institutional structures and educational outcomes rather than the use of minority language as a resource for responding to racism.

\subsubsection{Students' responses to racism outside the school}

In the case of racism outside the school students were more likely to opt for defensive and/or controlled strategies, usually by leaving the scene and/or ignoring the incident. For example, students assigned certain properties to the 'racist stranger', which reinterpreted the incident in certain ways that tended to minimize the problem (defensive strategy). More specifically, some students described the racist stranger as 'an extremist' and, therefore, a member of a minority group and not representative of the whole. Other students motivated their decision to 
ignore racism from strangers by stating that the stranger was 'somebody who doesn't know you', and as a result cannot really judge you. Finally, some students claimed that they did not care about racism from strangers as 'they are not your friend', suggesting that such experiences are not so harmful as the recipient of the message is somebody who does not have an emotional connection with the source. All these interpretations of the 'racist stranger' help to minimize the problem of racism, and together with 'leaving the scene' illustrate the most common defensive strategies employed by students in response to racism outside the school.

When compared to students' responses to racism inside the school, two factors emerge as significant: (a) the frequency and perceived duration of racist incidents over time; and (b) the availability of social support. First, our analysis shows that students' responses to racism in the street was associated with a perception of the event as 'one-off'; thus, suggesting that racism mainly needs to be confronted when it continues over time and becomes a more persistent problem:

Bafun: I would, I don't know, ignore them.

Researcher: Why? Why wouldn't you do something, with the student [in school] you would say something back?

Bafun: Because if it was a student from the school I see him every day, but if it was a guy from the street, I will not see him every day, just one time and I will ignore him [and] if I see someone every day, he will tell the things every day to me. (Interview Red Brick)

Another important difference between in and out of school contexts, is the perceived lack of social support that is otherwise available within the school. The lack of social support outside the school leads students to opt for more defensive strategies and escape the stressful 
situations, especially in cases when they feel outnumbered and confronted with threatening behaviour from strangers:

Vedat: And one time when I was with my father in the car, APOEL (a football team whose fans are associated with a right-wing political ideology) fans they came on motorbikes when we were in the traffic and they started hitting the car.

Researcher: And what did you do?

Vedat: You can't do anything, if we respond to them they would kill us and I know so many Turkish-Cypriot people I saw in the newspaper, their cars had been burned by APOEL fans.

(Interview Red Brick)

However, as soon as we changed the scenario and asked about an incident outside the school which involved peers from school, TC students often stated that they would report the incident afterwards to the senior management, suggesting that they choose a two-staged strategy with a counter-attacking second stage.

\section{Conclusions}

This article analyses qualitative interview data from Turkish-Cypriot students attending two urban, private secondary schools, in order to investigate the factors and processes that explain their preference for particular strategies in response to racism from Greek-Cypriots. This study builds on a rich body of research in sociology and social psychology by paying particular attention to the importance of and interactions between factors situated at the micro- and meso-level, such as face-to-face interactions and characteristics of organizations in explaining variability in TC students' responses to racism.

The findings suggest the usefulness of Mellor's (2004) classification of coping styles with racism, in which a distinction is made between (a) defensive, (b) controlled and (c) 
counter-attacking styles. In addition, our analyses also show the simultaneous or consecutive use of different types of strategies by the students, as well as the design of 'backup strategies' (i.e. 'plan B' strategies). These findings suggest that future research should take into consideration these more dynamic and complex ways in which actors can respond to racism. Finally, the study showed that students' responses to racism vary considerably according to context, with students generally showing more defensive strategies in response to strangers in the street and more counter-attacking strategies in response to racism from peers in school and - even more - in response to racism from teachers.

In addition, students' responses to racism from students appeared to vary between the two schools and particularly with respect to (a) the size (b) the ethnic composition of the student population and (c) the schools' policies in relation to racism. The analysis of these two case studies showed that smaller, and ethnically more heterogeneous schools, as well as school policies that take a clear and consistent anti-racist stance, with identifiable and trustworthy senior members of staff as recognized points of contact, seem to be in a good position to provide the necessary social support for ethnic minority students, since they tend foster a sense of social protection amongst ethnic minority students as well as closer interethnic relationships between students.

However, three characteristics of Green Lane's anti-racist policies interact to develop a situation in which minority students feel both protected but also more disliked by their GC peers: (a) overemphasizing the existence of the anti-racist policy in the school (b) allowing anti-racist school policies to be interpreted by the majority students as targeted against them and (c) displaying inconsistencies in the anti-racist approach. For these reasons, our analysis suggests that school structures aimed at protecting minorities from racism in school should make sure that the majority population does not feel unfairly targeted and does not perceive school policies as designed primarily to tackle racism from the majority group in school, as 
this can stimulate feelings of resentment towards minorities and further polarize in-out group relations in the school.

The latter point also illustrates how aspects of the school's social organization can impact the face-to-face relationships between actors in school. Our analysis suggests that, when available, students make use of institutional (in-school) support to respond to racism, thus applying more pro-active and counter-attacking strategies. By contrast, in out-of-school contexts, the lack of social support and the reduced frequency and duration of racist experiences can explain why the students interviewed opted much more for defensive strategies. Finally, with regard to teacher racism, students' initial (intense, controlled) response towards teachers seems to be informed by their educational aspirations and normative expectations for respect towards adults and teachers. At the same time, the social support available in school and at home, their understanding of the moral and instrumental incompatibility of racism in the fulfilment of the teachers' role and their confidence in their use of cultural resources in responding to racism, all encourage students to follow up such initial controlled strategies in response to teacher racism with more intense counter-attacking strategies.

Future research could focus on the experiences of and responses to racism of different ethnic minority groups in the context of Cyprus. Recent research suggests that the particular, historical and contemporary relationship between the dominant GC group and the various ethnic minority groups in Cyprus, result in different kinds of stereotypes of these minority groups (Stevens et al., 2014); stereotypes that intersect with gender (Spyrou, 2012) and social class (Zembylas, 2013a). Hence, it would be theoretically interesting to investigate the differences and similarities in how these minority groups in Cyprus respond to racism from GCs. Furthermore, research could also compare ethnic minority students' experiences of and 
responses to racism in Cyprus between international private schools, like the two schools included in this study, and state schools in Cyprus. The latter are often characterized by a more hellenocentric philosophy in terms of language of instruction (Greek) and expectations and perceptions of ethnic minority students, as expressed through school ceremonies (Zembylas, 2013b), textbook material (Papadakis, 2008), policy documents (Theodorou, 2014) and teacher-student classroom interactions (Spyrou, 2002). In addition, qualitative case-studies in other conflict-ridden societies that differ in terms of the historical development and contemporary intensity of the conflicts between the communities involved (e.g. Israel, Northern Ireland, Belgium), could further enhance our knowledge of how these macro characteristics interact with meso and micro contexts in shaping minority people's responses to racism. Furthermore, large-scale quantitative, multilevel analysis is ideally suited for estimating effects of factors (such as those which emerged from this study) situated on different levels of analysis simultaneously. In addition, researchers could also differentiate between students' experiences of and (complex) responses to different types of racism, such as racism in society in general and in particular social contexts (e.g. school, work), real and hypothesized experiences of racism and in relationship to actors that are different in terms of the power they can wield in certain contexts.

\section{Footnotes}

[1] Only pseudonyms are used in this article when referring to particular respondents or schools. 
[2] This information was obtained through analysis of survey data administered from a random sample of students in both schools (88\% of the students from Green Lane and $66 \%$ of the students from Red Brick participated with this survey).

\section{Bibliography}

BRONDOLO, E., BRADY VER HALEN, N., PENCILLE, M., BEATTY, D. and CONTRADA, R. J. (2009) Coping with Racism: A Selective Review of the Literature and a Theoretical and Methodological Critique. Journal of Behavioral Medicine, 32(1), 64-88.

BRONFENBRENNER, U. (1979) The Ecology of Human Development, (Cambridge, MA, Harvard University Press).

DOWNEY, D. B. (2008) Black/White Differences in School Performance: The Oppositional Culture Explanation. Annual Review of Sociology, 34(-), 107-126.

FORDHAM, S. and OGBU, J. U. (1986) Black Students' School Success: Coping with the Burden of Acting White. Urban Review, 18(-), 176-206.

FULLER, M. (1984) Black Girls in a London Comprehensive School. In M. HAMMERSLEY and P. WOODS (eds) Life in School. The Sociology of Pupil Culture. (Milton Keynes, Open University Press).

GILLBORN, D. (1990) 'Race', Ethnicity and Education. Teaching and Learning in Multi-Ethnic Schools, (London, Routledge/Falmer).

GILLBORN, D. and YOUDELL, D. (2000) Rationing Education: Policy, Practice, Reform and Equity, (Buckingham, Open University Press).

GLASER, B. G. (1992) Emergence vs. Forcing: Basics of Grounded Theory Analysis, (Mill Valley, Ca, Sociology Press).

GLASER, B. G. and STRAUSS, A. L. (1967) The Discovery of Grounded Theory: Strategies for Qualitative Research, (New York, Aldine).

HYERS, L. L. (2007) Resisting prejudice every day: Exploring women's assertive responses to antiblack racism, anti-semitism, heterosexism, and sexism. Sex Roles, 56(1-2), 1-12.

LAREAU, A. (1999 (1987)) Social-Class Differences in Family-School Relationships: The Importance of Cultural Capital. In A. H. HALSEY, L. HUGH, B. PHILIP and A. S. WELLS (eds) Education. Culture, Economy and Society. (Oxford, Oxford University Press).

MAC AN GHAILL, M. (1988) Young, Gifted and Black. Student-Teacher Relations in the Schooling of Black Youth, (Buckingham and Philadelphia, Open University Press).

MELLOR, D. (2004) Responses to Racism: A Taxonomy of Coping Styles Used by Aboriginal Australians. American Journal of Orthopsychiatry, 74(1), 56-71.

OGBU, J. U. (1990) Minority Education in Comparative Perspective. Journal of Negro Education, 59(1), 45-57.

PAPADAKIS, Y. (2008) Narrative, Memory and History Education in Divided Cyprus. History \& Memory, 20(2), 128-148.

RHAMIE, J. (2007) Eagles who Soar. How Black Learners find the Path to Success, (Stoke on Trent, Trentham Books). 
SCOTT, L. D. (2004) Correlates of coping with perceived discriminatory experiences among African American adolescents. Journal of Adolescence, 27(2), 123-137.

SEWELL, T. (1998) Loose Canons: Exploding the Myth of the 'Black Macho' Lad. In D. EPSTEIN, J. ELWOOD, V. HEY and J. MAW (eds) Failing Boys? Issues in Gender and Achievement. (Buckingham and Philadelphia, Open University Press).

SPYROU, S. (2002) Images of 'the Other': 'The Turk' in Greek Cypriot Children's Imaginations Race, Ethnicity and Education, 5(3), 255-272.

SPYROU, S. (2012) Children and the Sexualized Construction of Otherness: The Imaginary Perceptions of Russian and Romanian Immigrant Women in Cyprus. Journal of International Migration and Integration, 14(2), 327-343.

STEVENS, P. A. J. (2008) Exploring Pupils' Perceptions of Teacher Racism in their Context: A Case Study of Turkish and Belgian Vocational Education Pupils in a Belgian School. British Journal of Sociology of Education, 29(2), 175-187.

STEVENS, P. A. J. (2016) Ethnicity and Racism in Cyprus. National Pride and Prejudice?, (Basingstoke, Palgrave).

STEVENS, P. A. J., CHARALAMBOUS, P., TEMPRIOU, A., MESARITOU, E. and SPYROU, S. (2014) Testing the Relationship between Nationalism and Racism: Greek-Cypriot Students' National/Ethnic Identities and Attitudes to Ethnic Out-groups. Journal of Ethnic and Migration Studies, 40(11), 1736-1757.

STEVENS, P. A. J. and GÖRGÖS, R. (2010) Exploring the Importance of Institutional Contexts for the Development of Ethnic Stereotypes: A Comparison of Schools in Belgium and England. Ethnic and Racial Studies, 33(8), 1350-1371.

STEVENSON, H. C. (1998) Raising safe villages: Cultural-ecological factors that influence the emotional adjustment of adolescents. Journal of Black Psychology, 24(-), 44-59.

SWIM, J. K., HYERS, L. L., COHEN, L. L., FITZGERALD, D. C. and BYLSMA, W. H. (2003) African American college students' experiences with everyday racism: Characteristics of and responses to these incidents. The Journal of Black Psychology, 29(1), 38-67.

THEODOROU, E. (2014) Constructing the 'Other'. Politics and Policies of Intercultural Education in Cyprus. In L. VEGA (ed) Empires, Post-Coloniality and Interculurality. New Challenges for Comparative Education. (Rotterdam, Sense Publisher).

VRYONIDES, M. and SPYROU, S. (2014) Cyprus. In P. A. J. STEVENS and G. DWORKIN (eds) The Palgrave Handbook for Race and Ethnic Inequalities in Education. (Basingstoke, Palgrave).

WONG, C. A., ECCLES, J. S. and SAMEROFF, A. (2003) The Influence of Ethnic Discrimination and Ethnic Identification on African American Adolescents' School and Socioemotional Adjustment. Journal of Personality, 71(6), 1197-1232.

ZEMBYLAS, M. (2013a) Integrated Schooling in Divided Cyprus: Impossible or Indispensable? Studies in Ethnicity and Nationalism, 13(3), 442-454.

ZEMBYLAS, M. (2013b) Memorial ceremonies in schools: analyzing the entanglement of emotions and power. Journal of Political Power, 6(3), 477-493. 